\title{
Wenceslao E. Retana y la historia de Filipinas
}

\author{
antonio Caulín Martinez
}

La historia de Filipinas hasta hace pocas décadas ha resultado una de las grandes lagunas de la historiografía española, o al menos su estudio ha sido desproporcionado respecto a otras áreas geográficas donde la presencia hispana se cuenta por siglos. Esta falta de estudios, arrastrada quizás por la tendencia al «olvido» derivado del desastre del 98 , ha intentado paliarse por los trabajos de investigadores especialmente desde los años sesenta ${ }^{1}$.

Las recientes Jornadas sobre cincuenta años de Historiografía Americanista en España (1940-1989) y el I Simposium Internacional sobre el Extremo Oriente Ibérico coinciden en sus artículos sobre fuentes biblio-

Tras la crisis de 1898 los estudios filipinos en España comenzaron a descender, en el plano universitario desaparecieron y la bibliografía sólo se mantuvo por Retana. A raiz de la conmemoración del IV Centenario de la llegada a Filipinas, la Compañía General de Tabacos de Filipinas publica la Colección general de documentos relativos a las islas Filipinas (Madrid 1918-1923) y El descubrimiento del estrecho de Magallanes (Madrid 1920) del padre Pablo Pastells. Desde el término de la guerra civil y hasta la década de los cincuenta autores como don Julio Palacios, don Manuel Novas, el filósofo don José P. Bantug, don Amando G. Melon, etc., impulsaron los estudios sobre Filipinas. En 1953 se publicó el Catálogo de obras americanas y filipinas existentes en la Biblioteca Nacional por GUTIÉRAEZ CUESTA, Luisa y en 1958 Intramuros de Manila de 1571 hasta la destrucción en 1945 de Ortiz Amengol, Pedro. Al año siguiente Díaz TRECHUELo, María Lourdes, publicó Arquitectura española en Filipinas. El profesor don Leandro Tormo Sanz con sus trabajos y ánimos hacia sus alumnos, y la llegada a España del primer tomo de la Historia de Filipinas del historiador filipino MoLINA, Antonio, hacia 1960, supusieron un acicate e impulso definitivo para el restablecimiento de los estudios filipinos en España. Durante esta década las revistas como Razón y Fe, Indias, Missionalia Hispánica, etc., habian publicado una gran cantidad de monografias sobre Filipinas. En 1967 como asignatura optativa se imparte en la Universidad Complutense de Madrid "Historia de Filipinas" por el profesor don Leoncio Cabrero. Actualmente la Asociación Española de Estudios del Pacífico realiza una fructífera labor en este campo, el I Simposium Internacional sobre el Extremo Oriente Ibérico o la reciente aparición de la Revista Española del Pacifico son algunos ejemplos de este impulso. 
gráficas al subrayar la falta de estudios en general y el vacio casi absoluto de investigaciones relativas a la evolución de Filipinas en el siglo xIx, con algunas excepciones centradas en torno al "98».

El estudio de la Historia de Filipinas es, en ocasiones, el necesario complemento para comprender en todas sus dimensiones, no sólo la acción de España en América, sino la propia evolución de los acontecimientos internos peninsulares. Los trabajos sobre la evolución histórica del Archipiélago, en particular sobre el desconocido siglo xIX, pueden ofrecernos una serie de nuevas perspectivas que nos ayuden a entender muchos de los problemas intrínsecos españoles. El contraste de actitudes e ideologías en España y Filipinas arrojará unos fecundos resultados, óptimos para comprender la verdadera dimensión de ese siglo, tanto en la Península como en el Archipiélago.

El primer paso para rellenar esta laguna es crear un instrumento útil para averiguar con qué fuentes se cuenta. De ahí el presentar a Retana, un funcionario destinado en aquellas islas, con una personalidad muy crítica y objetiva, autor de una compilación de fuentes bibliográficas que, como veremos, resulta imprescindible para adentrarnos en la historia de Filipinas.

La lejanía del archipiélago asiático, la escasez de pobladores españoles, las comunicaciones largas y complicadas, entre otras causas, han relegado la historiografía al plano eclesiástico y más especialmente al misionero. En el siglo $x \mid x$ interviene un nuevo elemento que altera este panorama: el funcionariado. Un grupo humano obligado a desplazarse y a permanecer varios años en las islas. El Ministerio de Ultramar (consciente de la falta de conocimiento que existía sobre los restos de las posesiones ultramarinas), incentiva a este personal dependiente de la Administración, mediante una serie de premios, con el objeto de que realizaran estudios sobre el Archipiélago. Los trabajos sobre historia de las islas, hechos bajo esta presión, adolecian de objetividad, eran tendenciosos y giraban en torno a las autoridades del Archipiélago, para así conseguir el beneplácito necesario para un rápido regreso a España. La excepción en este grupo de autores es Wenceslao E. Retana, no por sus posicionamientos ideológicos (que los tuvo y se conocen), sino por sus compromisos con la objetividad en sus trabajos histórico-bibliográficos.

Retana, al contrario que otros funcionarios como Montero y Vidal ${ }^{2}$, no se atreve a realizar una "Historia global de Filipinas", lo considera una

2 MONTERo Y VIDAL, José, fue historiador de fines del siglo xix y funcionario en el Archipiélago como Retana. La historiografía actual lo ha utilizado mucho, principalmente dos de sus obras 
responsabilidad de gran entidad. Prepara, no obstante, el camino para futuros investigadores mediante una serie de trabajos históricos previos, y ofreciendo una compilación para la Historia general de Filipinas que titula Aparato Bibliográfico. Se distingue de otros funcionarios que realizaron trabajos sobre historia de Filipinas, al diferenciar bien el apasionamiento y la literatura, de la objetividad científica.

La biblioteca personal de Retana contenía una parte importante de libros filipinos, cuya colección los coetáneos tildaron de «la mejor de Europa". El interés de la Compañia General de Tabacos de Filipinas hizo que esa biblioteca se uniera con la que desde 1885 venía reuniendo en Barcelona el director de la empresa tabacalera. Los mecenas de esta compañía encargaron en 1905 a Retana, su clasificación y catalogación de cara a su publicación el resultado fue el Aparato Bibliográfico de la Historia General de Filipinas: las dos mejores bibliotecas filipinas unidas y reseñadas por un acreditado conocedor de la historia del país.

\section{WENCESLAO EMILIO RETANA Y GAMBOA, APROXIMACIÓN BIOGRÁFICA}

Retana habia nacido en Boadilla del Monte (Madrid) el 28 de septiembre de 1862, entró en la Academia de Ingenieros militares de Guadalajara, solicitando la separación del servicio a los dos años. Sin concluir estos estudios marchó con veintidós años a Filipinas como funcionario de $\mathrm{Ha}$ cienda en la Administración colonial, cargo que desempeñará hasta que cesó a petición propia y por motivos de salud (estaba enfermo del corazón), regresando a la Península en $1890^{3}$.

Durante los seis años que permaneció en el Archipiélago desplegó una gran actividad como periodista ${ }^{4}$; redactor de La Oceanía Española, y sub-

Historia de la piratería malayo-mahometana en Mindanao, Jolo y Borneo (Madrid 1888) e Historia general de Filipinas (Madrid 1887-1895, 3 vols.).

${ }^{3}$ "Cuando regresé a Filipinas, mi equipaje se reducia a dos baúles: uno de tamaño ordinario lieno de ropa y otro grande muy grande atestado de libros... muchos eran de Jagor, de Bowring, de Marche, de Montano, de Blumentritt, de Comyn, de José Felipe de Pan, del doctor Pardo de Tavera, de Isabelo de los Reyes". Y continúa criticando agudamente a los españoles que traian "Cuatro. seis y hasta diez o más baúles" cargados de recuerdos pretendidamente filipinos. Regresó con menos dinero del que se llevó y sus inversiones fueron los libros: "mi único ahorro consistía en libros, pero libros modestos que acaso todos juntos no valiesen arriba de 150 duros... de fecha reciente casi todos los cuales obstentaban honrosos autógrafos, con lo que quiero decir que habian sido regalados por sus respectivos autores". RETANA, W. E., "Revista Histórico Bibliográfica”, en Archivo del Bibliófilo Filipino. Madrid 1905, t. V, pág. 479.

${ }_{4}^{4}$ «Político y escritor, correspondiente de la Real Academia de la Historia. Redactor en 1891 y director en 1896 de la revista La Política de España en Filipinas. Ha colaborado también en 
director del semanario La Opinión ${ }^{5}$. Corresponsal de diarios como La España Oriental (Manila), El Porvenir de Bisayas (Cebú) y El Eco de Panay (lloilo). La mayoría de estos artículos firmados bajo el seudónimo de “Desengaños". En esta época publica El Indio batangeño ${ }^{6}$ un estudio sobre el folclore y costumbres de la provincia de Batangas ${ }^{7}$, y Transformismos: diálogos con un "bago" ${ }^{8}$ en el que critica a los españoles recién llegados y a sus ansias de un rápido enriquecimiento para poder regresar pronto a la Península. Volvió a Madrid en 1890 , y trajo consigo un hijo de pocos meses de edad fruto de su matrimonio en Batangas. Al poco tiempo consigue un puesto en el Ministerio de Ultramar y en 1896 llega a ser diputado y poco después gobernador de Huesca y Teruel. En Madrid consigue su actividad periodística en La Política Moderna, La Época, El Nacional, El Heraldo de Madrid y en varios periódicos extranjeros, siendo corresponsal de La Voz Española (Manila), y enviando artículos a El Renacimiento (Manila) a partir de $1904^{9}$.

Junto con estos artículos, los trabajos históricos y bibliográficos de Retana le llevaron a ser considerado un gran entendido en temas filipinos, en el general desconocimiento que sobre aquella colonia había en España, acentuado después de la crisis de 1898. La actividad periodistica e histórica la compaginó con su trabajo como funcionario y con la dedicación preferida de aumentar su todavía escasa biblioteca. Adquirió los primeros grandes lotes a Vindel, un librero que «compraba los libros poco menos

otros muchos periódicos como Nuestro Tiempo (1903), Guttemberg (1904) y pertenece a la Asociación de la Prensa de Madrid. Su curioso trabajo sobre el periodismo filipino será consultado con fruto por los que deseen conocer la institución en el Archipiélago citado". Ossorio Y BERNARD, Manuel, Ensayo de un catálogo de periodistas españoles del siglo xx. Madrid 1930, pág. 374. López de ZuAzo Algar, Antonio, en su obra, Catálogo de periodistas españoles del siglo xx (Madrid 1980-1981, pág. 500) escribe de Retana que era militar y escritor, ante lo que habría que puntualizar que el filipinista ingresó muy joven en la Academia de Ingenieros Militares de Guadalajara, de la que salió tras su solicitud de separación del servicio a los dos años.

5 Editor y ayudante de editor respectivamente, según ScHuMACHER, John N., Wences/ao E. Retana: An Historiographical Study. Manila, Philippine Studies, 1967, vol. 10, núm. 4, pág. 551.

6 Este estudio premiado en la Exposición Filipina de Madrid en 1887, fue pulicado por primera vez en La Oceania después en La España Oriental y la tercera edición corrió a cargo del propio Retana en 1888. Vid. la obra de SANTos Cristobal, Epifanio de los, Wenceslao E. Retana. Ensayo acerca de este ilustre filipinista. Madrid 1909, pág. 29.

7 Schumacher, op. cit., pág. 551

* La tercera edición (de 1889), tenía el subtítulo de Sátira de costumbres filipinas, sin embargo Epifanio de los Santos dice que es una sátira contra los españoles. Consúltese su obra ya citada, págs. 10-11 y 29.

${ }^{9}$ “Casi todos han sido comentadísimos y dado ocasión a no pocas controversias. En justicia puede decirse que nada de lo que Retana publica en El Renacimiento pasa inadvertido". SANTOS Cristóbal, Epifanio de los, op. cit, pág. 20. 
que al peso" ${ }^{10}$ en palabras del propio Retana. El bibliógrafo filipinista advirtió al librero de su especialidad y tras comprobar éste:

"Lo bien que le pagaba, huroneó, y un día -ioh sorpresa!- me anunció que deseaba mostrarme algunos de los muchos volúmenes que había comprado a la señora viuda de don José Cabezas de Herrera [Secretario del Gobernador General de Filipinas don Rafael Izquierdo 1872-1874]... me ofreció y yo compré, entre otras, las piezas siguientes:

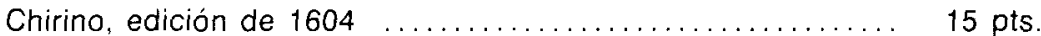

Aduarte y Santa Cruz (1693) ....................... 60 pts.

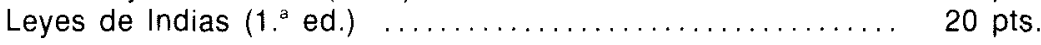

Aquellos libros antiguos despertaron en mí el amor al libro viejo; amor -que muchos no comprenden y que es a lo que pienso, el más sublime de los amores" ${ }^{11}$.

Al año siguiente de su regreso ya era diputado a Cortes y poco tiempo después Gobernador Civil de Huesca y Teruel. De modo que siempre compatibilizó su carrera política con los estudios históricos y bibliográficos. En 1892 fue secretario adjunto de los congresos internacionales de americanistas y orientalistas. En la revista quincenal La Politica de España en Filipinas colaboró junto con los hermanos Feced, contra una campaña financiada por los filipinos establecidos en Madrid, cuyo órgano de expresión fue la revista $L a$ Solidaridad ${ }^{12}$. Los folletos filipinos de Retana son cuatro pequeños libros que recogen las posturas "oficiales" contra la campaña dirigida por La Solidaridad, en los que defiende a los frailes y ataca personalmente a los colaboradores de ese quincenario. Continuando con este primer grupo de publicaciones que definen la ideología política de la primera época de Retana, en 1892 aparece Cuestiones filipinas: Avisos $y$ profecias con dos partes: en la primera reune una serie de artículos periodísticos sobre la política colonial en Filipinas y en la segunda recoge

10 Vindel era un librero madrileño más comerciante que bibliófilo, según se deduce de los comentarios de Retana. El filipinista colaboró en la preparación del catálogo de la biblioteca de Vindel haciéndole casi todas las reseñas de estos libros. Vid. la obra ya citada de SANTOS CRISTóbAL, Epifanio de los, pág. 32, y la "Revista Histórico Bibliográfica" de Retana, en Archivo del Bibliófilo Filipino. Madrid 1905, t. V, págs. 480 y ss.

"Retana, W. E., "Revista Histórico Bibliográfica", en Archivo del Bibliófilo Filipino. Madrid 1905 , t. V. pág. 480.

12 Los objetivos de este movimiento filipino eran: extender a Filipinas (y a los filipinos) los derechos de elección de diputados a Cortes que tenían los españoles peninsulares; expulsar las órdenes religiosas y confiscar de sus bienes; poner de manifiesto la cultura y originalidad del pueblo filipino. Esto último muy atacado por la sátira implacable de Retana. Después evolucionaría hacia posiciones menos radicales e incluso contrarias a las que en un principio había mantenido. SCHUMACHER, J., op. cit., pág. 553. 
y analiza algunos documentos relativos a la historia contemporánea del Archipiélago ${ }^{13}$.

En Filipinas, el precursor de la política redentorista trata el caso de Luis Rodríguez Varela, un criollo cuyos negocios se vieron perjudicados por su ideología de tendencia separatista. Este libro aparece en 1894, al igual que Supersticiones de los indios filipinos: un libro de aniterias, obra en la que, de nuevo Retana se encontraba inmerso en la campaña de enfrentamiento contra los filipinos, y ello pese a que incorpora en el texto una serie de oraciones en latín, castellano y dialecto pangasinam de gran valor antropológico y cultural ${ }^{14}$.

En Mando del General Weyler en Filipinas, aparecido en 1896, agrupa varios artículos periodísticos, defendiendo la gestión llevada a cabo por este gobernador general (1888-1891) ${ }^{15}$. Incorpora al texto una serie de documentos oficiales y privados, lo que redunda en el valor histórico de esta obra ${ }^{16}$. Tras el abandono de los hermanos Feced, Retana llega a ser editor de La Política de España en Filipinas, al tiempo que desaparece La Solidaridad (a finales de 1895). Estas circunstancias producirán un lento cambio en la orientación del quincenario dirigido por Retana que ya no cuenta con «oponente». Retana incluye entonces una serie de artículos históricos, lingüísticos, bibliográficos, que en ocasiones son el comienzo de sus futuros trabajos histórico-bibliográficos publicados por primera vez como artículos periodísticos en esta revista de la que era editor.

A lo largo de su vida Retana fue cambiando sus actitudes y puntos de vista respecto a algunos de los temas principales del mundo filipino del siglo xix: las órdenes religiosas, la identidad y peculiaridad cultural propia del archipiélago como base para el desarrollo de su autonomía y el héroe independentista Rizal. El reflejo de ello aparecerá en sus obras. La respuesta al por qué de esos cambios de actitud y la influencia que esto pudiera tener en sus trabajos científicos (no periodísticos) fue ya analizada en vida de Retana por el historiador filipino Epifanio de los Santos en un artículo Ilamándole «el ilustre filipino» ${ }^{17}$. Ambos, fueron ami-

13 Idem, pág. 553.

${ }^{14}$ Idem, pág. 554.

${ }^{15}$ Retana, W. Emilio, El mando del General Weyler en Filipinas. Madrid 1898

${ }^{16}$ Weyler fue Gobernador General de Filipinas cuando Retana estaba en el Archipiélago, y éste a su vez fue nombrado Inspector-General de Policia de Barcelona (de 1911 a 1918) durante el mandato de Weyler como Capitán General de Cataluña. Puede ser una interesante hipótesis de trabajo comprobar si existe alguna relación en estos nombramientos. Sabemos por su correspondencia que Retana no se encontraba bien en Barcelona porque no podia trabajar (en sus obras histórico-bibliográficas) como en Madrid. Archivo Franciscano Ibero-Oriental (AFIO), carta de Retana al padre Lorenzo Pérez de 15 de octubre de 1923, sign. 214/51-1.

17 Santos Caistóbal, E. de los, op. cit., pág. 9 
gos y colaboradores, lo que nos aconseja precaución en cuanto a la opinión de éste. Poco después apareció un folleto anónimo titulado Filipinerias: A propósito de un folleto, el cual era una réplica a la obra de De los Santos, argumentando que Retana era un oportunista y que su cambio de actitud obedecía al interés financiero para que se publicaran sus obras tras la caída del régimen español ${ }^{18}$. Sin entrar en esta discusión, sí podemos trazar dos etapas en la evolución del pensamiento político de Wenceslao E. Retana. La primera desde que llega a Madrid y hasta que deja de publicarse La Solidaridad (1890-1895), en la que:

- Defendió las órdenes religiosas como elementos sustentadores de la soberanía española en Filipinas.

- Atacó a los propagandistas filipinos, menospreciando a los colaboradores de ese movimiento y las características propias filipinas, que eran argumentadas por aquellos en su solicitud de un mayor grado de autonomía.

En la segunda etapa (de 1895 hasta su muerte en 1924), Retana comienza a darse cuenta de los abusos producidos por algunos frailes y respecto a los artículos contra los propagandistas son simplemente superados (o sustituidos) por otros menos polémicos y más científicos: temas históricos, lingüísticos, bibliográficos, historia de la imprenta, etc. ${ }^{19}$. $\mathrm{Su}$ obra Folletos filipinos: I. Frailes y cléricos ${ }^{20}$ publicada en 1890, tuvo una edición ocho años después con el título Los frailes filipinos por un español que ha residido en aquel pais ${ }^{21}$ en la que suprime algunos de los párrafos ofensivos para los filipinos, aunque todavía no ataca a los frailes como más tarde hizo ${ }^{22}$.

Como parece deducirse de su escasa producción, 1898 es un año de reflexión ante los significativos cambios que se estaban produciendo. Continuó manteniendo contactos con historiadores y bibliófilos filipinos, y con sus antiguos amigos. Tras la crisis del «98», la enfermedad que le había traído de Filipinas le impidió continuar con sus investigaciones históricas y bibliográficas, aunque sus libros y artículos continuaron apareciendo. A esto se añadió el quebranto de su situación económica (después de haber

18 SChumacher, J., op. cit., pág. 569.

19 Otras posturas, en cuanto a su evolución político-ideológica, son recogidas por ScHu. MACHER, Idem, págs. 569-570.

${ }^{20}$ Existe una segunda parte de esta obra: Folletos Filipinos II. Apuntes para la historia. (Aniterias y solidaridades). Madrid, Imprenta de Minuesa de los Ríos, 1890.

21 Retana, W. Emilio, Los trailes filipinos, por un español que ha residido en aquel pais. Madrid, Imprenta de Vda. Minuesa de los Ríos, 1898.

22 SCriumacher, opus cit., págs. 569-570. 
publicado varios libros de su propio bolsillo), entre ellos cuatro de los cinco tomos del Archivo del Bibliófilo Filipino ${ }^{23}$. Se vio obligado a vender su biblioteca personal una colección de dos mil setecientos títulos. Las intenciones de Retana eran que sirviera de base a una futura Biblioteca Nacional de Filipinas "pero los amigos filipinos con quien yo había mantenido correspondencia dejaron de escribirme..." ${ }^{24}$.

Se puso en contacto con los agustinos, concretamente con el comisario en Madrid "el Padre Fr. Tomás Fito, que me profesaba verdadero afecto" y con el padre Navarro "a quien había yo contagiado de bibliomanía». El valor de la transacción fue fijado por ambas partes en 25.000 pesetas. Aunque las autoridades de la orden de Manila desaprobaron la compra, Retana cobraba ya (sin la autorización filipina) de las arcas de estos religiosos en Madrid, 5.000 pesetas mensuales, por lo que sus amigos agustinos buscaron un comprador: la Compañía General de Tabacos de Filipinas con sede en Barcelona (destino último de la “Colección») ${ }^{25}$. La retirada de los libros y documentos del depósito de Retana tuvo lugar en el verano de 1900. Tres años después un norteamericano ofreció a Retana, ignorando que ya estuviera vendida, 50.000 dólares por su biblioteca. Hacia 1904 Retana recibió el encargo de la Compañía de Tabacos de catalogar esta colección junto con los más de dos mil títulos filipinos que esta empresa ya poseía ${ }^{26}$.

A partir de aquel año, los artículos de Retana en El Renacimiento de Manila revelan un cambio significativo. Estos escritos iban dirigidos a ridiculizar a las órdenes religiosas y alababan las peculiaridades del pueblo filipino. Después de la publicación en 1911 de su obra Orígenes de la Imprenta en Filipinas su laboriosidad volverá a disminuir hasta concluir su mandanto como Inspector-General de la Policía de Barcelona en 1918.

${ }^{23}$ Retana, W. E., Archivo del Bibliófilo Filipino. Recopilación de documentos históricos, cientificos, literarios y políticos y estudios bibliográficos. Madrid, t. I, 1895; t. II, 1896; t. III, 1897 y t. IV, 1898. El tomo $V$ apareció en 1905 y a diferencia de los otros no fue costeado por Retana, sino por el editor Victoriano Suárez.

${ }^{24}$ Retana, W. E., "Revista Histórico Bibliográfica", en Archivo del Bibliófilo Filipino. Madrid 1905 , t. V. págs. 481 y 482.

${ }^{25}$ «... el señor Sánchez [bibliotecario de la Compañia] con el catálogo en la mano, uno a uno fue encajonando los libros... Y yo me quedé sin ellos, y poco tiempo después, sin ninguno de los cinco mil duros en los que los había dado...". Idem, págs. 481 y ss.

${ }^{26}$ «Es el trabajo que en breve aparecerá con el título Aparato Bibliográfico de la Historia General de Filipinas, deducido de la mejor colección del mundo... en tres volúmenes en folio. La Compañia Tabacalera me ha dispensado el honor de encomendarme a mí, sin regateos de ninguna clase, la tarea de ejecutar la obra. Próxima a salir a la luz los filipinistas apreciarán. más que el mérito de lo por mí ejecutado, la riqueza de esa incomparable colección, en la que hay quince o veinte ejemplares únicos, más de cien rarísimos y acaso unos quinientos que pueden reputarse raros". Idem, págs. 481 y ss. 
Los últimos años de la vida de Retana están reflejados en gran parte en la correspondencia que mantiene con el padre Lorenzo Pérez (OFM) encargado del Archivo Franciscano en Pastrana (con fondos procedentes en su mayoría de las misiones en Asia), entre 1921 y 1923. En ellas menciona la conclusión de algunos de sus trabajos pendientes: el Índice de personas nobles..., los artículos para la Enciclopedia Espasa Calpe; y a investigadores (Gómez Platero), bibliófilos (los padres Pérez y Güelmes, Graiño) ${ }^{27}$, editores (Victoriano Suárez), y autores literarios, etc. Carta a carta describe su merma en la salud, sus frecuentes ataques de asma, quejándose de que "no puedo escribir y apenas leer alguna cosa» ${ }^{28}$. Sus problemas caseros y la preocupación por sus hijos ${ }^{29}$, son otros temas continuos en esta correspondencia.

Retana llegó a decir "me he hecho muy religioso" ${ }^{30}$, acudiendo a misa casi a diario y confesando regularmente. Sus cartas están jalonadas de referencias a la voluntad Divina en la que ha depositado sus esperanzas de curación o su destino final. Unos meses antes de morir (febrero de 1924) dice a su amigo el padre Lorenzo que lamenta irse de este mundo $\sin$ “redondear mis trabajos editoriales», pero está agotado e incluso no puede escribir el discurso de ingreso en la Real Academia de la Historia $^{31}$.

Los cinco últimos años de vida están caracterizados por la objetividad de sus trabajos, sin especial referencia a cuestiones polémicas y el retracto en alguna de sus opiniones más radicales respecto a las órdenes religiosas. La defensa que hace Retana de las órdenes, en un principio, se debe a la idea compartida con otros muchos españoles en las islas, de que el poder de la Iglesia era el único capaz de sostener el Gobierno

\footnotetext{
27 Retana describe la intensa colaboración con Antonio Graiño. Le contagió su inquietud por "los libros raros", desarrollando su interés en esta materia. De las numerosas referencias a Graiño en varias de sus cartas parece deducirse que Retana le introdujo en el ambiente, entre bibliófilos y posteriormente el filipinista se vio "abandonado"; en sus cartas finales se lamenta de que no vaya a visitar "a este enfermo" [subrayado de Retana]. AFIO, carta de Retana al padre Lorenzo Pérez de 15 de octubre de 1923, sign. 214/51-1.

${ }^{28}$ AFIO, carta de Retana al padre Lorenzo Pérez de 2 de enero de 1922, sign. 214/51-7.

${ }^{29}$ Llega a revisar y preparar una nueva edición de sus trabajos "para si con posterioridad a mi muerte alguien quiere editarlos en beneficio de mis hijas". AFIO, Idem de 4 de abril de 1922 , sign. 214/51-4

${ }^{30}$ AFIO, Idem de 23 de octubre de 1922, sign. 214/51-6.

31 «Excuso decir a Vd. que dado mi estado de salud, mi esperanza de curación, es en declinación continua, renuncio a escribir el discurso de ingreso en la Academia de la Historia. No puedo. Pero es que aun haciendo un esfuerzo para escribir cosa breve, ¿cómo leerlo? Para no poder asistir a la Academia ¿para qué ingresar?». AFIO, Idem de 15 de octubre de 1923, sign. 214/51-1.
} 
español en Filipinas. Algunos autores interpretan la modificación de la postura de Retana como deshonesta, mientras que otros ensalzan los valores científicos del bibliógrafo e historiador, olvidando los puntos de vista personales del filipinista ${ }^{32}$. La fama y prestigio de bibliógrafo y filipinista se extendió, llegando a ser miembro de varias sociedades históricas, nacionales y extranjeras ${ }^{33}$; alcanzando diversas condecoraciones en reconocimiento a su labor, a propuesta de la Real Academia de la Historia $^{34}$.

\section{PRODUCCIÓN INTELECTUAL DE RETANA}

La obra de este filipinista abarca el periodismo ${ }^{35}$, las obras de historia y su producción biliográfica. Dejamos conscientemente al margen su escasa, pero valiosa, obra literaria ${ }^{36}$ abandonada por una mayor dedicación a la recopilación bibliográfica y a la historia.

${ }^{32}$ De los Santos así to manifiesta en la Advertencia introductoria de su libro sobre Retana "Cualesquiera que hayan sido sus opiniones políticas, nos haya o no tratado con dureza antaño, nosotros los filipinos desapasionados no podemos negar que es Retana el primero de los investigadores de primera mano, y así resulta que sus obras de carácter histórico y bibliográfico han venido a convertirse en fuentes indispensables de consulta". SANTOS CRISTOBAL, E. de los, op. cit., pág. 21. Schumacher en cambio, apoyándose en el autor anónimo de Filipinerías, dice de Retana que con sus elogios posteriores a 1904, buscaba una fuente de financiación para sus obras. Ante este argumento habría que razonar sobre el Retana comprador de libros filipinos y editor de sus trabajos históricos y de fuentes documentales cuyos originales están hoy perdidos. Añadamos a este planteamiento que en verano de 1904, el bibliófilo ya había vendido su biblioteca a la Compañia de Tabacos y estaba en la imprenta de Victoriano Suárez el quinto y último tomo del Archivo del Bibliófilo... Al no ser objeto del presente estudio ahondar en esta interesante polémica, es preferible valorar (y tener en consideración científica), sus trabajos históricos y bibliográficos, dejando para sus biógrafos aquellos textos (periodísticos en su mayoría), políticamente controvertidos.

${ }^{33}$ Miembro de las Sociedades Geográficas de Berlín y Viena, miembro del Instituto de las Indias Neerlandesas de La Haya, miembro de la Real Academia de la Historia con el título de Filipinista. Encomienda ordinaria y de número de la orden de Alfonso XII. Vid. de Retana, Aparato Bibliográfico de la Historia General de Filipinas. Madrid 1906, ed. facsímil: Manila, Historical Conservation Society, 1967, e Indice de las personas nobles y de otra calidad que han estado en Filipinas desde 1521 a 1898. Madrid 1921.

${ }^{34}$ Catalina Garcia, Juan, "Informe. Historia General de Filipinas" [se refiere a la obra de Retana Aparato Bibliográfico de la Historia General de Filipinas], Boletin de la Real Academia de la Historia. Madrid junio de 1907, vol. L, págs. 413 a 426 .

${ }^{35}$ Me he referido a esta producción en el epígrafe anterior de aproximación biográfica.

${ }^{36}$ Cejador y Frauca, J., Historia de la Lengua y Literatura Castellana. Madrid 1919, t. X. Consúltese las referencias a las opiniones de Retana sobre la literatura filipina (extraidas de su obra De la evolución de la literatura castellana en Filipinas. Madrid 1919), en págs. 68 y 69 ; y sobre el valor literario de sus obras las págs. 131-135. Estas son Aguas fuertes. Obra dramática en tres actos. Madrid 1901 y la novela La tristeza errante. Barcelona 1933 (ed. definitiva). Emilia Pardo Bazán dijo de él que era el único (junto con Felipe Trigo) de entre los nuevos autores 


\section{Retana como historiador}

En esta faceta escribió varios artículos sobre la historia del Archipiélago, pero su primer trabajo de importancia son las notas y apéndices que hace a la obra del padre Joaquín Martínez de Zúñiga Estadismo de las islas Filipinas ${ }^{37}$, publicada a iniciativa del propio Retana en 1893. El texto era un manuscrito inédito de gran valor por ser la primera descripción completa del Archipiélago a principio del siglo xIX. Tanta importancia como la obra en sí, tienen las notas y apéndices que realiza Retana, elogiadas por el filipinista austríaco Blumentritt, pese a que en el terreno político, y sólo en un principio, discrepó (llegando a mantenerse un enfrentamiento dialéctico en la prensa) de Retana. Algunos autores posteriores consideraron estas notas de mayor valor que el trabajo original ${ }^{38}$. José Toribio de Medina, el gran bibliógrafo chileno, que estaba trabajando entonces sobre bibliografia filipina, elogió tanto las notas al texto de Martínez de Zúñiga como la parte bibliográfica añadida por Retana.

Precisamente este autor, José Toribio Medina, en 1896 publicó La imprenta en Manila desde sus origenes hasta 1810 que dedicó a Retana. Éste le contestó con un suplemento de unos doscientos títulos ${ }^{39}$, junto con sus observaciones críticas y correcciones dedicándoselo a su vez al bibliógrafo chileno. Además, sentó las bases para una futura y fructífera discusión sobre los origenes de la imprenta en Filipinas: Medina decía que procedía de Mancao, y Retana que era originaria de Manila, apoyán-

que se dedican al análisis personal y "su única novela por ahora, [sería también la última] La tristeza errante le ha ganado un puesto discutito y un público interesado y numeroso. Retana estudia la pasión, pero es a la vez un sátiro despiadado de las costumbres de la alta sociedad, que describe reunida en una estación balnearia. El cuadro es sombrio, tal vez exageradamente, y hay en su libro, amén de mucho talento, algo de violento y amargo que fuerza la atención y no permite que pasen inadvertidos, en esta época de excesiva producción novelesca, ni el autor ni la obra". PARDO BAZAN, Emilia, "La nueva generación de novelistas", en Helios. Madrid 1904, año II, núm. 12, págs. 266-267. Sobre la valoración de sus obras literarias principales y sus repercusiones inmediatas puede consultarse la "Crónica literaria" de BUENo, Manuel [sobre La tristeza errante]. en La correspondencia de España de 3 de septiembre de 1903, y el Heraldo de Madrid de 16 de septiembre de 1897 [sobre Aguas fuertes].

32 Rodriguez, Isacio, Gregorio Aglipay y los origenes de la iglesia filipina independiente (1898-1917). Madrid, Biblioteca "Missionalia Hispánica", vol. XIII, Departamento Misionalogia Española (CSIC), 1960, t. I, pág. 30

${ }_{38} \mathrm{Vid}$. las opiniones que el propio Retana recoge de su edición en Aparato Bibliográfico de la Historia General de Filipinas (ed. facsímil de la publicada en 1906 por la Compañia General de Tabacos de Filipinas. Manila. Historical Conservation Society, 1964, vols. I, II y III), núm. de reseña 3365. (Cito el número de orden de la reseña o ficha de la publicación y no el tomo y página de esta obra por ser más fácil su localización.)

${ }^{39}$ Me refiero a la publicada por Retana, La imprenta en Filipinas (1593-1810) (con el subtitulol Adiciones a la Imprenta en Manila de Medina. Madrid 1899. 
dose en pruebas históricas que incorpora. En 1904 Medina publicó una serie de notas adicionales a los dos textos anteriores reconociendo sólo algunas de las pruebas aportadas por Retana y manifestando su desacuerdo. En las Tablas cronológicas (Madrid 1908), Retana desarrolló las pruebas históricas ya expuestas en la Imprenta en Filipinas, pero ahora incorporando las ideas de Medina y de los padres agustinos Pérez y Güemes (investigadores en este campo), dando además un catálogo cronológico de las imprentas conocidas en Filipinas y de los impresores (localizadas geográficamente). Finalmente, respecto a la cuestión de los orígenes de la imprenta en el Archipiélago, publicó en 1921 una monografía extensa demostrando sus tesis con nuevas pruebas históricas, bibliográficas y topográficas Origenes de la Imprenta en Filipinas: Investigaciones históricas, bibliográficas y tipográficas, reproduciendo facsimiles de varios de los primeros ejemplares publicados en las islas.

La documentación inédita que Retana incorporó y publicó en su Archivo del Bibliófilo filipino ${ }^{40}$ hacen de estos cinco tomos una fuente imprescindible para el conocimiento de la historia de Filipinas. Manuscritos etnológicos, lingüísticos, históricos, documentos políticos de actualidad (sobre los primeros pasos de la revolución filipina), etc., de gran importancia para el investigador ya que algunos de estos originales se dan hoy por perdidos o desaparecidos.

La Historia de Mindanao y Joló del padre jesuita Francisco Combés había sido publicada en Madrid en $1667^{41}$. En colaboración con el padre Pablo Pastell (también jesuita) Retana edita de nuevo este texto, enriqueciéndolo y completándolo con nuevos datos históricos y lingüísticos, añadiendo una extensa bibliografía. En el prólogo, el editor (Retana) dice que las notas a la obra de Combés son del padre Pablo Pastell y la bibliografía es aportación suya, lo cual parece evidente, ya que Retana tres años antes había publicado Bibliografía de Mindanao ${ }^{42}$.

Junto con el Aparato Bibliográfico de la Historia General de Filipinas, la mayor contribución de Retana es la Vida y escritos del Dr. José Rizal publicada en Madrid en 1907. Retana conoció poco a Rizal pero sí a muchos de sus seguidores y amigos de los que recibió (tras condenar

40 Vid. nota 23.

${ }^{4}$ Combes, Francisco, Historia de Mindanao y Joló, con la colaboración del padre Pablo Pastell, prólogo y estudio preliminar de RetanA. Madrid 1909.

42 Retana, W. E., Bibliografia de Mindanao. Epitome. Madrid 1894. "La Bibliografia de Mindanao es un catálogo comprensivo de ciento setenta y cuatro notas correspondientes... a obras referentes a un país que tanto nos importa conocer a los españoles". La Época 5 de septiembre de 1891 
públicamente su fusilamiento) toda la colaboración, contanto para este trabajo con fuentes epistolares inéditas (publicadas por primera vez en esta obra). Retana dedicó esta biografía a su antiguo enemigo político el filipinista austríaco Blumentritt ${ }^{43}$. En 1908 publica La censura de imprenta en Filipinas donde estudia las actas de las sesiones de la Comisión Permanente de Censura en Manila (del 23 de junio de 1866 al 23 de abril de 1875), y las comunicaciones de esta comisión ${ }^{44}$. Ese mismo año, aparece La Primera Conjuración separatista, 1587-1588, un folleto de veinte páginas publicado también en 1908 en El Renacimiento de Manila. Utilizó una serie de documentos inéditos del Archivo de Indias, pero está revestido de esa ideología contra las órdenes religiosas, propia de esta época.

En 1909 realizó una nueva edición de los Sucesos de las islas Filipinas de Antonio Morga (publicada por primera vez en México en 1609). Al igual que en la obra anterior no se limitó a copiar simplemente el texto de la antigua edición sino que incorporó nuevos documentos para clarificar el texto ${ }^{45}$ extraídos de los archivos españoles. En la extensa introducción incorpora una biografía del doctor Morga «por nadie escrita hasta el presente" en palabras de Epifanio de los Santos ${ }^{46}$. Esta edición constituye todavía una útil aproximación a la primera etapa del asentamiento hispano en Filipinas.

Tras concluir su mandato en la inspección de Policía de Barcelona en 1918, Retana vuelve a los trabajos históricos de Filipinas en la época colonial, aportando buenos ejemplos de erudición, investigación y rigor científico. La revista madrileña Raza Española (en marzo de 1921), publicó uno de estos nuevos estudios coloniales de Retana bajo el título índice de las personas que acudieron al descubrimiento de las islas Filipinas ${ }^{47}$.

\footnotetext{
43 "Quien se apresuró a acusar recibo del libro, diciéndole al autor [Retana] en atentísima carta: "Usted erigió al malogrado patriota el más importante monumento, que le agradecerá todo el pais; pero también todos los que - no conociendo límites políticos ni plataformas de partido ni preocupaciones de raza - rindan culto a todo espíritu grande", SANTos Cristóbal, E. de los, op. cit., pág. 22.

${ }_{44}$ "Prueba el autor [Retana] que siempre hubo censura en Filipinas desde los comienzos de la dominación española hasta el 13 de agosto de 1898, excepto contadísimos años del período comprendido entre 1813 y 1824". Idem, pág. 20.

${ }^{45}$ SCHUMACHER, J., op. cit., pág. 558.

${ }^{46}$ Santos Cristóbal, op. cit., pág. 21.

${ }^{47}$ Al respecto, el Boletín de la Real Academia de la Historia recogia la siguiente critica: "... El trabajo del señor Retana es de una escrupulosidad admirable. Rectifica muchos errores, y expone las principales andanzas conocidas de los que tomaron parte en aquella memorable expedición, deteniéndose especialmente en las figuras de Juan Sebastián Elcano, Gonzalo Gómez de Espinosa, Hernando de Magallanes y Antonio de Pigafetta, presumido italiano, que escribió la crónica de la expedición, y cuya obra, como dice el señor Retana "debe ser acogida
} 
Otro trabajo de gran importancia es el Índice de las personas nobles y de otra calidad que han estado en Filipinas desde el descubrimiento hasta $1898^{48}$, publicado en el Boletín de la Real Academia de la Historia en 1921 y ese mismo año, separadamente, por el editor Victoriano Suárez. Retana en la introducción dice que este trabajo que es sólo una parte de otro que llevará el título de La Nobleza española en las islas Filipinas, que a su vez es una parte de otro proyecto de mayor envergadura denominado Los apellidos españoles en el Extremo Oriente ${ }^{49}$.

\section{Como bibliógrafo}

Aparte de sus trabajos como editor de obras como las de Combes, Morga y Martínez de Zúniga, o los trabajos inéditos aparecidos en el Archivo del Bibliófilo, la figura de Retana interesa como bibliógrafo ${ }^{50}$. El interés de Retana por la bibliografia comienza a su regreso de las Filipinas. Según indicamos al principio, cuando vuelve a Madrid no to hace con más dinero del que se llevó trayendo únicamente libros. En 1893 publica su primer trabajo bibliográfico que comprende los libros que contenía su biblioteca personal en aquel momento.

Al año siguiente, publica la Bibliografía de Mindanao realizada a raíz de la idea (expresada en un periódico) de la escasez de obras sobre estas islas y que Retana con este trabajo trata de rebatir ${ }^{51}$. La bibliografía anotada, cuenta con numerosos trabajos de autor español, aunque tam-

con ciertas reservas", pues omite en ella deliberadamente los nombres de los españoles". BoNILLA y San Martín. A., "Un estudio patriótico", en Boletín de la Real Academia de la Historia. Madrid noviembre de 1921, t. LXXIX, pág. 433.

${ }^{48}$ RetANA, W. E., Indice de las personas nobles y de otra calidad que han estado en Filipinas desde 1521 hasta 1898. Madrid, Librería de Victoriano Suárez, 1921

${ }^{49}$ El motivo de estos estudios obedece a que "se ha dicho y repetido hasta la saciedad, que España mandó a sus colonias lo PEOR de cada casa. Por lo que respecta a Filipinas (la última de las colonias españolas, por la distancia y por el rendimiento), ese dicho no deja de ser un tópico, desgraciadamente consagrado por el uso de gentes más o menos cultas, pero de criterio de muy accesible a lo razonable». RETANA, W. E., Indice de las personas nobles..., pág. 5.

${ }_{50}$ Me referiré en este apartado a las recopilaciones bibliográficas con excepción de su obra principal Aparato Bibliográfico de la Historia General de Filipinas que trataré ampliamente en los dos siguientes epigrafes. Sobre la valoración de este trabajo y sus repercusiones inmediatas cf. Catalina Garcia, Juan, op. cit. (págs. 413 a 426). Villar, Emilio H. del, "Bibliografia Filipina. Una obra monumental", en Nuevo Mundo. Madrid 9 de mayo de 1907.

${ }^{51}$ «Hícelo en ocho dias, respondiendo a los lamentos de no sé qué periódico diario de Madrid, el cual se quejaba de que apenas existiese nada escrito acerca de dicha isla. Inventarié ciento setenta y cuatro títulos, dispuestos por orden cronológico". RetamA, W. E., Aparato Bibliográfico..., t. I, pág. VI. 
bién obras extranjeras, probablemente procedentes de la biblioteca de Blumentritt ${ }^{52}$. En años sucesivos publicó varios artículos más reducidos sobre bibliografía de Filipinas, al tiempo que adquirió libros relativos a las islas o bien los «fichaba" de los principales bibliófilos españoles, siguiendo un plan ${ }^{53}$. En 1895 comenzó a publicar un «Epítome» sobre bibliografía en las páginas del Archivo del Bibliófilo ${ }^{54}$. En los cuatro primeros volúmenes (publicados en 1895, 1896, 1897 y 1898), aparecieron mil ciento sesenta y siete títulos, anotados y comentados, pero cuando dejó de publicarse temporalmente (el quinto tomo apareció en 1905), determinó publicar en un solo volumen el catálogo entero de su biblioteca, lo que hizo ese mismo año bajo el título Catálogo abreviado de la biblioteca filipina de Wenceslao E. Retana (Madrid 1898) ${ }^{55}$. Éste junto con otros trabajos sobre bibliografía son la base de lo que luego sería su gran aportación.

\section{HISTORIA Y FORMACIÓN DE UNA BIBLIOTECA}

Hasta el momento conocemos la figura de Wenceslao E. Retana bibliógrafo que se preocupó por reunir unas dos mil publicaciones (libros, cartas, discursos, órdenes, etc.) con el denominador común de ser de origen filipino o estar relacionado con este Archipiélago ${ }^{56}$. Pero ¿cómo se formó la Biblioteca de Retana, dónde fue adquiriendo sus volúmenes, qué apoyo recibió, cuál fe el valor que se le dio, qué motivos le impulsaron a crearla, etc.

A la enorme actividad desarrollada como periodista a su llegada a Madrid en 1890, Retana busca y publica (con su propio dinero) aquellos trabajos inéditos que hemos explicado anteriormente. Junto a estas dedicaciones, preparaba diversos estudios históricos y ensayos políticos algunos de los cuales tuvieron enorme éxito, especialmente los que aventuraban una realidad confirmada en 1898.

52 Schumacher, J., op. cit., pág. 564.

${ }^{53}$ Vid. nota 58.

${ }^{54}$ En el epígrafe siguiente describo más ampliamente este "Epítome".

${ }^{55}$ «... la parte material de la obra tanto la que se refiere a la impresión de la orla, a las signaturas... revelan en el señor Retana la escrupulosidad, el esmero y la inteligencia de un verdadero bibliófilo,... la edición consta de treinta ejemplares". La Época 3 de abril de 1893.

${ }^{56}$ Como expliqué al principio la biblioteca de Retana (o "colección" como su creador le llama), fue unida a la biblioteca que sobre Filipinas tenía la Compañía General de Tabacos en Barcelona. Esta colección definitiva de cuatro mil seiscientas veinticuatro fichas o reseñas fue publicada, previa catalogación del propio Retana, con el título de Aparato Bibliográfico de la Historia General de Filipinas a instancias de la Compañia de Tabacos, en tres gruesos volúmenes en 1906 
La razón de crear esta colección residía en que, según Retana «no podrá hacerse nada perfectamente acabado ínterin no conozcamos todos cuantos elementos existen que puedan facilitarnos el trabajo" y añade: "yo que he venido con verdadera perseverencia durante cuatro años coleccionando libros [1891-1895], y acopiando noticias de los que no poseo, comienzo ahora la publicación de un "Epítome de la Bibliografía general Filipina" bajo un plan...»" ${ }^{57}$. Efectivamente Retana publicó entre 1895 y 1898, cuatro volúmenes bajo el título Archivo del Bibliófilo Filipino, que contenía el "Epítome de bibliografía filipina" con publicaciones relativas a la colección de libros y documentos que iba agrupando. En 1905 apareció el volumen $V$ del Archivo, que ya no tenía el “Epítome» pero sí en cambio la "Revista Histórico Bibliográfica». El plan al que hace referencia consistía en catalogar cronológicamente: “ $1 .^{a}$ Las obras que poseo. 2. ${ }^{a}$ Las que he registrado por mí mismo en bibliotecas públicas y particulares, y que yo no poseo. $3 .^{a}$ Las que, no hallándose comprendidas en ninguno de los dos grupos anteriores, consten en obras de bibliografía, biografías, historia, etc. ${ }^{58}$. Este era el diseño de su trabajo, la necesidad de la publicación de sus fondos residía en el apremio con que los historiadores le consultaban sobre si tenía este o aquel libro, así lo explica:

"Terminada que sea mi tarea, la cerraré con un índice alfabético de autores y traductores que facilite el manejo de los diez o doce tomos [sólo se publicaron cinco, sin embargo la totalidad está en el Aparato Bibliográfico] en que ha de ir el "Epítome". Este plan, que yo mismo califico de extravagante, responde a las exigencias de la conciencia y aun de la conveniencia; abrumado por bibliófilos que de mí solicitan informaciones..." ${ }^{59}$.

Los objetivos de su plan, entresacados del prólogo al tomol de su «Epítome» publicado en 1895, son una auténtica declaración de principios e intenciones de un filipinista preocupado por la recopilación de publicaciones sobre el Archipiélago, a la vez que deseaba adelantarse «al homenaje que necesariamente habrán de rendir bibliófilos y escritores el día que se celebre el CUARTO CENTENARIO DEL DESCUBRIMIENTO DE FILIPINAS" ${ }^{60}$.

${ }^{37}$ Retana, W. E., Archivo del Bibliófilo..., t. I, pág. XXXVII.

${ }^{53}$ Idem, pág. XXXVIII.

59 Idem, págs. XXXVII-XXXVIII

${ }^{60}$ Las intenciones de Retana, las he agrupado en seis apartados: " $1 .{ }^{\circ}$ Servir a los que deseosos de estudiar en las fuentes primitivas determinados asuntos filipinos, no pueden verificarlo sin embargo, porque no les es dable trasladarse a Europa, en algunos de cuyos archivos y bibliotecas existen esas fuentes que a través de los años han llegado a desaparecer del país 
En 1896 aparecía el segundo volumen de este «Epítome», en el que figuraban doscientas treinta y cinco reseñas, de las dos mil que pretendía dar "sólo de la Primera parte» según explica en el prólogo, es decir, de los libros que poseía. No hizo referencia a la segunda (reseñas recogidas de bibliotecas, de libros que él no poseía), ni a la tercera parte (fichas hechas a partir de las citas que encontrase en los libros). La biblioteca la obtiene en su mayor parte mediante adquisiciones a libreros. Recibe algunos regalos de autores filipinos (libros que había traido de Manila), y textos de catequesis religiosa en tagalo y visaya de las diversas órdenes. Fueron varios los religosos de los que obtuvo numerosos ejemplares ${ }^{61}$. En ocasiones era de los libreros ${ }^{62}$ o de eruditos ${ }^{63}$ de los que obtenía las publicaciones de forma gratuita.

En la reseña número 940 del Aparato Bibliográfico (los Estatutos de la Universidad de Santo Tomás), dice que este «ejemplar fue... cedido graciosamente a la colección, como algunas otras piezas, por D. Clemente Miralles ${ }^{64}$, que adquirió en venta la magnífica biblioteca que habia pertenecido al mencionado académico..." ${ }^{65}$. En una de las partes de su “Re-

donde tuvieron origen... 2. ${ }^{\circ}$ poner al alcance de todas las fortunas la copia fiel de papeles preciosos por su rareza o por su indiscutile utilidad... $33^{\circ}$ sacar del polvo en que yacen manuscritos de interés, y darlos a la luz para provecho de todos... $4 .^{\circ}$ lanzar al campo de la controversia datos nuevos que pueden contribuir a la resolución de las cuestiones pendientes aún del fallo definitivo entre historiadores, geógrafos, lingüistas y, en general, entre todos aquellos que cultivan cuanto se relaciona con los paises del Extremo Oriente donde España ha ejercido o continúa ejerciendo más o menos influencia... $5 .^{\circ}$ contribuir a que no queden inéditos trabajos estimables de autores contemporáneos, que por una u otra causa no pueden dar a la imprenta el fruto de sus estudios... $6 .^{\circ}$ fomentar la afición a la bibliografía filipina, por ser éste el mejor medio de patentizar lo que alli la inteligencia ha producido y lo que aqui se ha trabajado en obsequio de aquel pedazo de España...”. Idem, págs. XII-XIV.

${ }^{61}$ Los religiosos de los que obtiene libros son: Rmo. señor don fray José Hevia Campomanes, Obispo de Nueva Segovia; fray Lesmes Pérez, párroco de Antique; fray Cipriano Marcilla, párroco de Batac (llocos Norte); fray Buenaventura Campa, procurador general de los dominicos; fray Aquilino García ("libritos de propaganda religiosa en ilocano"). RetanA, W. E., Archivo del Bibliófilo..., t. I, pág. XXXIX.

${ }_{62}$ "He sido favorecido con una importante remesa que me ha hecho de regalo mi querido amigo don José González Páramos". RetanA, W. E., Archivo del Bibliófilo..., t. II, pág. XXI.

${ }_{63}$ De don Francisco Zapater que "fue un grande amante de las obras sobre Filipinas. Reunió muchas, y no pocas de ellas vinieron a mi poder (las cuales figuran hoy en esta COLECCIÓN); son contadas las que no tienen aportaciones marginales y otros signos que denotan que fue Zapater un estudioso". RetanA, W. E., Aparato Bibliográfico..., núm. 699. Refiriéndose a la obra del padre fray Juan Félix de la Encarnación Estadística de la Provincia de San Nicolás Tolentino de los PP. Agustinos Recoletos de Filipinas dice que este "ejemplar... fue acribillado de curiosas notas de este erudito e ilustrado bibliófilo [refiriéndose a Zapater]". RETANA, W. E., Aparato Bibliográfico..., núm. 615 .

${ }_{64}$ Clemente Miralles de Imperial era director de la Compañía de Tabacos cuando comenzó a formarse la biblioteca de esta empresa, bajo su impulso en 1885

${ }^{65}$ Retana, W. E., Aparato Bibliográfico..., núm. 668. 
vista Histórico Bibliografica" en la que agrupa fichas de libros inéditos y que él Ilama "Papeletas Bibliográficas -inéditas--», aparece en numerosas ocasiones la publicación reseñada como "ejemplar de D. Antonio Graiño", por to que hemos de suponer que este bibliógrafo, amigo personal de Retana, le remitió algunas de las fichas que aparecen en el Aparato Bibliográfico.

Lo anterior se refiere a los regalos y cesiones gratuitas de libreros, recopiladores y bibliógrafos, pero la parte principal de su biblioteca la fue adquiriendo de los principales libreros europeos: Vindel, de Madrid; Quaritch, de Londres; Muller, de Amsterdam; Hiersemann, de Leipzig; Rosental, de Munich ${ }^{66}$; Martinus Nijhoff, de La Haya; etc., por los que «desembolsé en ocho años, unos cinco mil duros»" ${ }^{67}$.

Victoriano Suárez, editor y financiador del quinto volumen del Archivo del Bibliófilo (Madrid 1905) cuenta en el «prospecto» de esta publicación:

"Cuantos conozcan la Bibliografía de Filipinas no podrán negar lo mucho que se ha trabajado en obsequio de los conocimientos históricos de aquel país; pero ya sea porque faltó a unos espíritu investigador, ya por que adolecieron otros de excesivo celo patriótico, ya, finalmente porque ninguno de ellos dispuso de todas las fuentes originales indispensables para conocer la verdad con todos sus pormenores, bien puede decirse que la Historia del Archipiélago Filipino es una historia imperfectamente propagada, deficiéntemente conocida... de un tiempo a esta parte obsérvase entre los filipinos una avidez extraordinaria de conocer su pasado; pero luchan con el grave inconveniente (a lo menos los que no pueden venir a investigar en los archivos y bibliotecas de Europa), de no disponer de todos los elementos necesarios. Pensando en esto, el conocido filipinista Sr. Retana ideó en 1895 una interesante publicación..." ${ }^{68}$.

El valor del Aparato Bibliográfico reside precisamente en rellenar ese vacio sobre relaciones bibligráficas de una zona en la que España había estado presente durante siglos (al igual que América). Probablemente al unirse la biblioteca personal de Retana con la que poseía la Compañía General de Tabacos en Barcelona, se formó la mejor compilación biblio-

${ }^{66}$ En la Revista Histórico Bibliográfica, hace referencia a la primera obra en latín (de 1523) obtenida de un librero alemán: «... transcribo esta papeleta [se refiere a la reseña bibliográfica] de la que acaba de comunicarme en carta particular [fechada en Munich, el 15 de septiembre de 1905] el rico e inteligente librero señor Ludwing Rosental que me ofrece el ejemplar (único hasta hoy conocido y no citado ni por incidencia en ninguna bibliografía) en mil marcos solamente...". Retana, W. E., Archivo del Bibliófilo..., t. V, pág. 485.

67 Retana, W. E., "Revista Histórico Bibliográfica", en Archivo del Bibliófilo Filipino. Madrid 1905, t. V, pág. 481.

68 Retana, W. E., Archivo del Bibliófilo..., t. V, pág. VII. 
gráfica de temas filipinos ${ }^{69}$. Juan Catalina García, que analizó profundamente el contenido del Aparato Bibliográfico en un informe presentado a la Real Academia de la Historia concluye:

"Sirva de remate a este informe una calurosa felicitación a la Compañia de Tabacos de Filipinas, no sólo por la suerte que tiene de poseer tan notable colección de impresos y por la esplendidez con que los ha catalogado, sino por el acierto de haber diputado para el trabajo de la catalogación a un filipinista tan prestigioso y a un bibliógrafo tan excelente como lo es el Sr. Retana. En virtud de este juicio, tengo la honra de proponer a la Academia: 1. ${ }^{a}$ Que declare su satisfacción por el mérito extraordinario de la obra de su Correspondiente [se refiere a Retana] $2{ }^{2}{ }^{2}$ Que pida al Sr. Ministro de Instrucción Pública que otorgue al Sr. Retana una recompensa adecuada al expresado mérito. Madrid, $10 \mathrm{de}$ mayo de $1907{ }^{70}$.

En consecuencia la reacción (que se produjo de forma inmediata), tanto en Filipinas como en España, fue la de valorar como fuente imprescindible de consulta el Aparato Bibliográfico ya que previa catalogación y comentario del propio filipinista unía ambas bibliotecas ${ }^{71}$. Epifanio de los Santos, después de una rápida ojeada por la bibliografía estadounidense relativa a las recopilaciones sobre series de libros similares al Aparato Bibliográfico, concluye tres años después de su publicación:

"Casi todo el material bibliográfico de Filipinas, sean sus fuentes manuscritas o impresas, debiéronse a plumas castellanas y hállanse casi

\footnotetext{
${ }^{69}$ Retana, once años antes de publicarse el Aparato Bibliográfico... (desconocia por lo tanto la futura agrupación), había dicho en la biblioteca de la Compañia de Tabacos: "De mi biblioteca nada tengo que decir; algunos creen que, en su especialidad, es la mejor que existe en Europa; yo no puedo afirmarlo, y menos no conociendo al detalle la que tiene la Companía General de Tabacos, que es magnifica". RETANA, W. E., Archivo del Bibliófilo.... t. I, págs. XXXVIII-XXXIX.

${ }^{70}$ Catalina Garcia, Juan, "Informe. Historia General de Filipinas", en Boletin de la Real Academia de la Historia. Madrid junio de 1907, t. L, pág. 426

"Todas las publicaciones catalogadas y anotadas en el Aparato... componen ahora la colección que desde 1883, y por iniciativa de su director don Clemente Miralles, empezó a formar en Barcelona la Compañia General de Tabacos de Filipinas, y que enriquecida con la del señor Retana y con lo más selecto de la de Vindel, ha venido a ser, sin disputa, la mejor del mundo en su materia. Con esto y con recordar una vez más lo que representa la personalidad del señor Retana en materia de estudios filipinos, queda expuesto, sin necesidad de hiperboles, lo que significa el Aparato Bibliográfico... que acaba de publicarse... y que en adelante dará lo primero que deba consultar todo aquel que pretenda hacer estudios sobre la geografía, historia, filología o literatura de aquel Archipiélago». VILLAR, Emilio H. del, “Bibliografia Filipina». en Nuevo Mundo. Madrid 9 de mayo de 1907. Sobre la evolución posterior de las bibliotecas de Retana y de la Compañía, su traslado a Manila en 1913 y su desaparición durante la Segunda Guerra Mundial, puede consultarse Giralt Reventos, Emili, La Compañia General de Tabacos de Filipinas, 1881-1981. Barcelona 1981 (págs. 171-180).
} 
todas en España, por imperio de las circunstancias que a nadie se ocultan, no será mengua de nadie que, de cuantos se han dedicado a estas ciencias y que, por ende escribieron en castellano, el primer investigador de historia y bibliografía de Filipinas, sea el Sr. Retana... En la riquísima serie The Philippine Islands, sus editores no pocas veces disintieron de sus dictámenes, pero tuvieron el buen acuerdo de utilizar libremente el material dejado por él... ${ }^{72}$ el Aparato es la mayor obra de bibliografía filipina que existe, y la más importante fuente de estudio sobre impresos, que justifica harto razonablemente el título Aparato Bibliográfico de la Historia General de Filipinas. Pero si para el filipinista este libro constituye un monumento de excepcional importancia para el bibliógrafo en general no vale menos: el juicio que ha merecido a la Rea| Academia de la Historia de Madrid, es concluyente, la sabia Corporación se deshace en elogios, los más subidos, y acaba por proponer al Gobierno de S. M., que premie al Sr. Retana con una recompensa extraordinaria» ${ }^{73}$.

En 1976 fue publicada la Bibliografia descriptiva y crítica de libros filipinos de Don Antonio Graiño por Carlos Sanz ${ }^{74}$. Esta compilación está compuesta por aquellas reseñas de publicaciones del insigne librero, amigo de Retana. Para la confección de estas “fichas" o reseñas el autor utiliza de manera habitual el Aparato Bibliográfico, junto con otras recopilaciones bibligráficas filipinas como la de Videl o Pardo de Tavera, por lo que su vigencia actual como fuente general bibliográfica queda respaldada.

\section{LA COMPILACIÓN BIBLIOGRÁFICA FILIPINA DE RETANA COMO FUENTE PARA LA HISTORIA DEL SIGLO XIX FILIPINO ${ }^{75}$}

Una vez visto el origen, formación, composición, valoración, etc., de la biblioteca de Retana y su unión con la que ya poseía la Compañía de Tabacos, a continuación describo cómo puede ser aprovechado el resul-

\footnotetext{
72 Santos Cristóbal, Epifanio de los, op. cit., pág. 27.

73 ldem, pág. 15.

74 SAnz, Carlos, Bibliografía descriptiva y critica de libros de don Antonio Graiño. Manila, Instituto Nacional de Historia, 1976, págs. 189-282.

${ }^{75}$ En este epígrafe me refiero a la utilidad del Aparato Bibliográfico... como fuente bibliográfica. En cuanto a las fuentes documentales del Archipiélago pude consultarse CÉSPEDES DEL CASTILLO, Guillermo, "Textos y documentos de la América Hispánica (1492-1898)", Historia de España, dirigida por Manuel Tuñón de Lara. Barcelona 1986, t. XIII, págs. XLVII-LXXXV; “Sección I. Fuentes documentales" en Actas del I Simposium Internacional sobre el Extremo Oriente Ibérico. Madrid 1989, págs. 17 a 257; SÁNCHEZ BELDA, Luis, Guia de fuentes para la Historia de Asia en España. Munich, Londres, Nueva York, Paris, Dirección de los Archivos Estatales de España/Unesco, 1987; Caukshank, Bruce, "Filipiniana in Madrid", Philippines Studies Ocassional Papers. Honolulu mayo de 1984, núm. 6.
} 
tado de esa catalogación y clasificación que este cilustre filipinista», según Epifanio de los Santos, hiciera en el Aparato Bibliográfico de la Historia General de Filipinas ${ }^{76}$. Dividido en tres volúmenes recopila desde las primeras noticias sobre Filipinas hasta el año 1905, con un total de cuatro mil seiscientas veintitrés fichas bibliográficas.

Este material compilado y ordenado por Retana es una fuente imprescindible a tener presente. El investigador que quiere adentrarse en la Historia de Filipinas puede servirse del Aparato Bibliográfico de dos maneras: como una primera lista bibliográfica de referencias que luego habrá que filtrar conforme a su campo especifico de trabajo y como fuente bibliográfica en sí misma dado el "contenido" de las reseñas, es decir aprovechará los comentarios de Retana a las fuentes bibliográficas que analice, sus estudios comparativos, crítica de fuentes utilizadas por los autores, etc.

Las obras de historia de Filipinas, las "relaciones" y "estados generales", las fuentes epistolares, las "memorias" de los gobernadores generales y las guías de viajeros son por su gran aportación de datos un conjunto de fuentes bibliográficas imprescindibles para el conocimiento de forma general de la historia de Filipinas. Los trabajos sobre "derroteros marítimos", "perimetros costeros" y otras descripciones geográficas junto con los estudios estadísticos sobre población (por ejemplo los de fray Manuel Blanco) y aquellos realizados a instancia de la Comisión Central y luego Junta General de Estadística ayudarán a los especialistas a trazar la evolución geográfica y demográfica.

Para la historia económica Retaña reseña las interesantes Juntas de Accionistas del Banco Español-Filipino (desde su comienzo en 1854), junto con las balanzas comerciales y mercantiles. Respecto a la historia política de Filipinas, el Aparato Bibliográfico contiene una gran cantidad de

\footnotetext{
${ }^{76}$ "Denominado asi porque en sus páginas se contiene la referencia de todos los elementos que son precisos para escribir la historia general del Archipiélago". SANTOS CRISTÓBAL, Epifanio de los, op. cit., pág. 13. Manejo para este estudio la edición facsímil de la Historical Conservation Society (publicada en Manila en 1966), que respeta la distribución que Retana hiciera cuando el Aparato Bibliográfico... fue publicado por primera vez en 1906. El primer volumen recoge el material publicado hasta 1800 , contiene cuatrocientas cincuenta y ocho fichas. El segundo y el tercero (de 1801 a 1905) contienen cuatro mil ciento noventa y cinco, que se ordenan de la siguiente manera:
}

I.a) Publicaciones del siglo xıx, del núm. 459 al 4132.

b) Pulicaciones del siglo $x \mid x$, sin fecha, del núm. 4133 al 4297 .

II.a) Publicaciones del siglo xx, del núm. 4298 al 4445

b) Publicaciones del siglo $x x$, sin fecha, del núm. 4446 al 4460.

III. El periodismo filipino (1811-1905), núm. 4461 al 4623. 
fuentes: las "propuestas" (0 «manifiestos a la nación») realizadas por los grandes personajes, «discursos", "sermones», «alocuciones» y los interesantes "diálogos" (en los que se pone en boca de dos personajes ficticios posiciones ideológicas antagonistas derivando la conversación -o el "diálogo" - hacia la postura del autor). También para la historia de la cultura o de la Iglesia existen conjuntos de reseñas útiles para el investigador en estos campos.

En conclusión Retana, principal filipinista español, dejó un legado valiosísimo el Aparato Bibliográfico del cual podemos utilizar las propias observaciones y críticas del filipinista y crear una primera relación de publicaciones que después depuraremos conforme a los objetivos de nuestra especialidad. Siguiendo las ideas expuestas por José María Jover en su conocido artículo El siglo xIx en la historiografía española contemporánea (1939-1972) ${ }^{77}$ : necesidad de especialización en este caso en la compleja, complementaria y desconocida Historia de Filipinas; rescatar y conservar las fuentes del siglo xix del Archipiélago partiendo de la figura de Retana (como principal intérprete de esa historia) y de un instrumento útil por él creado el Aparato Bibliográfico de la Historia General de Filipinas.

Jover Zamora, José María, "El siglo Xix en la historiografía española contemporánea" (1939-1972), en El siglo xix en España, doce estudios. Barcelona, Planeta, 1972, págs. 9-152. 